\title{
Jaroslav Fiala \\ Powder Diffraction Editor for Eastern Europe
}

I am pleased to announce that Dr. Jaroslav Fiala has accepted the POWDER DIFFRACTION staff position as geographic Editor for Eastern Europe and northern Asia. Dr. Fiala has been associated with POWDER DIFFRACTION for several years as the correspondent to the International Report describing activities in eastern Europe and preparing many book and meeting reviews. Dr. Ludwik Gorski has agreed to replace Dr. Fiala as the correspondent for Eastern Europe.

Dr. Fiala began his career in 1964 in the X-ray powder diffraction laboratory of the Central Research Institute SKODA, Plzen, Czech Republic following graduation from Charles University in Prague. His responsibilities were the analysis of many hundreds of samples of metals and alloys in particular along with ceramics, polymers, corrosion products, and many other materials typical of any industrial laboratory. During these analyses, he became interested in the problems of phase quantification. In the late 1970s, he published calculated patterns for ten carbides and nitrides that occur in steels.

Other studies lead Dr. Fiala to computerization of phase identification and the development of systems used in several laboratories in eastern Europe. The problem of identification of phases in complex systems using microanalysis led to the use of the Kossel technique for local particle analysis.

In the 1980s, Dr. Fiala employed factor analysis as a promising tool for standardless quantitative powder diffraction. The goal was to overcome real structural effects. Interest in the structural effects led to his organization of the highly successful International Conference on Size/Strain in Liptovsky, Mikulas, Slovakia with P. Sutta and R. L. Snyder. The proceedings for this conference should be published in the near future as an IUCr Monograph.

Dr. Fiala's most recent interests deal with epi-(endo-, topo)taxy as a feature in solid state chemistry and materials engineering and the use of powder diffraction for monitoring the products. This field is a new use of the Powder Diffrac- tion File for the design of protective coatings and solid composites.

Since 1992, Dr. Fiala has been teaching part-time at the West-Bohemian University in Plzen and since 1993 also at the Technical University of Mining and Metallurgy in Ostrava where since 1997, he has been Full Professor of Materials Engineering. He is an editor for the journal "Materials Structure in Chemistry, Biology, Physics and Technology", and a member of the Editorial Boards of "Kovove materialy" (Metallic Materials) and "Powder Diffraction". He has served as a member of the IUCr Commission on Powder Diffraction from 1990 to 1996 and has been a member of the International Centre for Diffraction Data since 1992. He is a founding member of the Engineering Academy of the Czech Republic and is Vice Chairman of the Crystallographic Association of Czech and Slovak Crystallographers. At present he is involved in organizing the 18th European Crystallographic Meeting to be held in Prague in August 1998.

Authors in eastern Europe are encouraged to forward their Powder Diffraction manuscripts to Dr. Fiala for processing. Using the editor closest geographically assists both the author and editor by simplifying the correspondence. Of course, the boundary between eastern and western Europe is imaginary and up to the author.

Correspondence with Dr. Fiala should be addressed to:

Prof. Jaroslav Fiala

SKODA Research Ltd.

31600 Plzen, Czech Republic

Phone: 42019-773-4335

FAX: 42019-773-3889

E-mail: jaroslav.fiala@vsb.cz (one week each month) 